Review Article

\title{
Endotoxin-Induced Tryptophan Degradation along the Kynurenine Pathway: The Role of Indolamine 2,3-Dioxygenase and Aryl Hydrocarbon Receptor-Mediated Immunosuppressive Effects in Endotoxin Tolerance and Cancer and Its Implications for Immunoparalysis
}

\author{
Elisa Wirthgen and Andreas Hoeflich \\ Institute of Genome Biology, Leibniz Institute for Farm Animal Biology, Germany \\ Correspondence should be addressed to Elisa Wirthgen; wirthgen@fbn-dummerstorf.de
}

Received 28 August 2015; Revised 28 October 2015; Accepted 6 December 2015

Academic Editor: Mario Herrera-Marschitz

Copyright (C) 2015 E. Wirthgen and A. Hoeflich. This is an open access article distributed under the Creative Commons Attribution License, which permits unrestricted use, distribution, and reproduction in any medium, provided the original work is properly cited.

\begin{abstract}
The degradation of tryptophan (TRP) along the kynurenine pathway plays a crucial role as a neuro- and immunomodulatory mechanism in response to inflammatory stimuli, such as lipopolysaccharides (LPS). In endotoxemia or sepsis, an enhanced activation of the rate-limiting enzyme indoleamine 2,3-dioxygenase (IDO) is associated with a higher mortality risk. It is assumed that IDO induced immunosuppressive effects provoke the development of a protracted compensatory hypoinflammatory phase up to a complete paralysis of the immune system, which is characterized by an endotoxin tolerance. However, the role of IDO activation in the development of life-threatening immunoparalysis is still poorly understood. Recent reports described the impact of inflammatory IDO activation and aryl hydrocarbon receptor- (AhR-) mediated pathways on the development of LPS tolerance and immune escape of cancer cells. These immunosuppressive mechanisms offer new insights for a better understanding of the development of cellular dysfunctions in immunoparalysis. This review provides a comprehensive update of significant biological functions of TRP metabolites along the kynurenine pathway and the complex regulation of LPS-induced IDO activation. In addition, the review focuses on the role of IDO-AhR-mediated immunosuppressive pathways in endotoxin tolerance and carcinogenesis revealing the significance of enhanced IDO activity for the establishment of life-threatening immunoparalysis in sepsis.
\end{abstract}

\section{Introduction}

Each day, animal organisms are exposed to a multitude of immunological stressors and pathogens, and they react with appropriate immune responses. For a successful host defense, a balance between pro- and anti-inflammatory parts of the immune response is essential. A loss of this balance leads either to an overreaction or to a suppression of immune response, both of which could be life-threatening situations. Within this regulation of immune response, the degradation of tryptophan (TRP) along the kynurenine pathway plays a crucial role. This pathway is a major link between the immune and nervous systems [1]. In the context of immune response, indoleamine 2,3-dioxygenase 1 (IDO1) is the rate-limiting enzyme for the degradation of tryptophan (TRP) along the kynurenine pathway to biologically active metabolites, such as kynurenine (KYN), kynurenic acid (KYNA), or quinolinic acid (QUIN), which have been shown to take part in diverse physiological and pathological processes [2]. IDO1 is activated by proinflammatory cytokines as a part of innate immunity and has different physiological functions with a highly cell type specific pattern of inducibility. The immunosuppressive function of IDO1 activation was shown for the first time in murine placenta [3]. The high expression of IDO1 in the placenta leads to a local suppression of maternal immune response and protects the fetus from rejection 
by its mother. Even in malignancies, it has been shown that an increased IDO1 activity promotes the development of an immune tolerance protecting the tumor against the immune response [4]. In patients with sepsis, an increased IDO1 activity provokes systemic immunosuppression and is associated with an increased risk for mortality, when it is used as a prognostic indicator for probability of survival $[5,6]$. In addition to the immunological consequences, the modulation of TRP metabolism influences the nervous system and behavior. The activation of the kynurenine pathway in the brain, depletion of TRP, and generation of neurologically active metabolites are associated with diseases including schizophrenia [7], Alzheimer's disease [8], and depression $[9,10]$.

\section{Tryptophan Metabolism as a Link between Nutrition and Immune and Nervous System}

TRP as an essential amino acid is not synthesized by the animal organism. Therefore, dietary TRP is transported from the digestive tract through the portal vein to the liver where it is used for the synthesis of proteins [11]. In numerous cell types, approximately $95 \%$ of the dietary TRP is metabolized via the kynurenine pathway $[2,12]$. For a long time it was thought that TRP is only completely oxidized to $\mathrm{NAD}^{+}$ (coenzyme) or to ATP (energy source) in liver cells, but it has been shown that this occurs also in extrahepatic cells (e.g., in astrocytes) [13]. In many cell types, the metabolites of the kynurenine pathway mediate mainly anti-inflammatory effects [14] whereby they act regulatory in response to proinflammatory stimuli. In cells of the nervous system KYNA, anthranilic acid (AA), 3-hydroxyanthranilic acid (3HA), or QUIN modulate neurological functions. KYNA acts as an antagonist of the glutamate receptor and is therefore described as a neuroprotective metabolite, whereas QUIN, an agonist of the glutamate receptor, mediates neurotoxic effects [15]. In addition to its importance in the kynurenine pathway, the degradation of TRP to serotonin (5-HT) and to melatonin in cells of the pineal gland has important physiological functions. 5-HT acts both as a hormone and as a neurotransmitter. Melatonin acts as a neurohormone and is associated with the development of circadian rhythm and the sleep-wake cycle [16]. Because the expression of enzymes along the kynurenine pathway may differ substantially between specific cell types, a crude classification of four compartments was made [11]. The first compartment includes cells of somatic tissues, such as the lungs and intestines, where TRP is mainly degraded to KYN. In addition to the immunosuppressive effects of KYN, it has been shown that KYN acts as an endothelium-derived relaxing factor that is able to decrease blood pressure in hypertensive rats [17]. The second compartment contains cells of the immune system, such as dendritic cells or macrophages, which express many enzymes of the kynurenine pathway, exclusive of enzymes for the synthesis of the coenzyme nicotinamide adenine dinucleotide $\left(\mathrm{NAD}^{+}\right)$, which is required for redox reactions in cells. Hepatic cells represent the third compartment and express all enzymes required for the total oxidation of TRP.
In the fourth compartment, including cells of the central nervous system, TRP is specifically degraded to KYNA, but other neurologically active metabolites, such as quinolinic acid, are also generated. Additionally, KYNA has been found to be generated by macrophages [18]. Increased concentrations of KYNA and xanthurenic acid (3-Hydroxy KYNA, XA) were detected in the plasma of patients with type 2 diabetes, presumably due to chronic stress or the low-grade inflammation that are prominent risk factors for diabetes [19]. Thermochemical and kinetic data show that KYNA and XA are the best free-radical scavengers from the eight tested TRP metabolites [20], suggesting that the production is a regulatory mechanism to attenuate damage by the inflammationinduced production of reactive oxygen species. AA and 3HA can act as antioxidants in certain chemical environments but, in the presence of iron(II), 3-HA exhibits prooxidant activity [21]. Patients suffering from neurological disorders as Huntington's disease or brain injury often showed decreased levels of 3-HA combined with increased levels of AA [22]. However, the biological importance of the 3-HA to AA ratio as either neurotoxic or neuroprotective mechanism is still discussed [22, 23].

One characteristic of TRP metabolism is that the ratelimiting step of the catalysis from TRP to KYN is generated by both the hepatic enzyme tryptophan 2,3-dioxygenase (TDO) and the ubiquitous expressed enzyme IDO1 [24, 25]. TDO is essential for homeostasis of TRP concentrations in organisms and has a lower affinity to TRP than IDO1. Its expression is activated mainly by increased plasma TRP concentrations but can also be activated by glucocorticoids and glucagon [26]. In contrast to TDO, IDO1 expression is specifically induced by inflammatory stimuli, such as the cytokines TNF- $\alpha$ or IFN- $\gamma$. IDO has a high affinity to L-tryptophan but will also catalyze the oxidation of other substrates, such as serotonin (5-HT) or melatonin [27]. It has been assumed that TDO is only expressed in the liver; however, studies in mice indicate that TDO is also expressed in the brain $[28,29]$. In addition to IDO1 and TDO, IDO2 is described as the third rate-limiting enzyme of the kynurenine pathway [30]. IDO1 and IDO2 share a significant identity at the amino acid level but are not structurally related to TDO. IDO2 is predominantly expressed in the kidneys, followed by the epididymis, testis, and liver [31]. The expression in distinct cell types as well as the response to stimuli differs, suggesting that IDO1 and IDO2 are not functionally redundant [31]. IDO2 has even been found to be expressed in human tumor cells, but the physiologically significant degradation of TRP to $\mathrm{KYN}$ is catalyzed by IDO1 [32]. At present, the biological function of IDO2 is not well established. Recent studies indicate that IDO2 is a critical mediator in the production of autoantibodies [33] and in IDO1-mediated T cell regulation in the context of inflammation [34]. The existence of three ratelimiting enzymes differing in structure, substrate specificity, and activation supports the significance of the kynurenine pathway for both nutritional and immunoregulatory functions. An overview of the TRP degradation pathways and their biological significance is presented in Figure 1. 

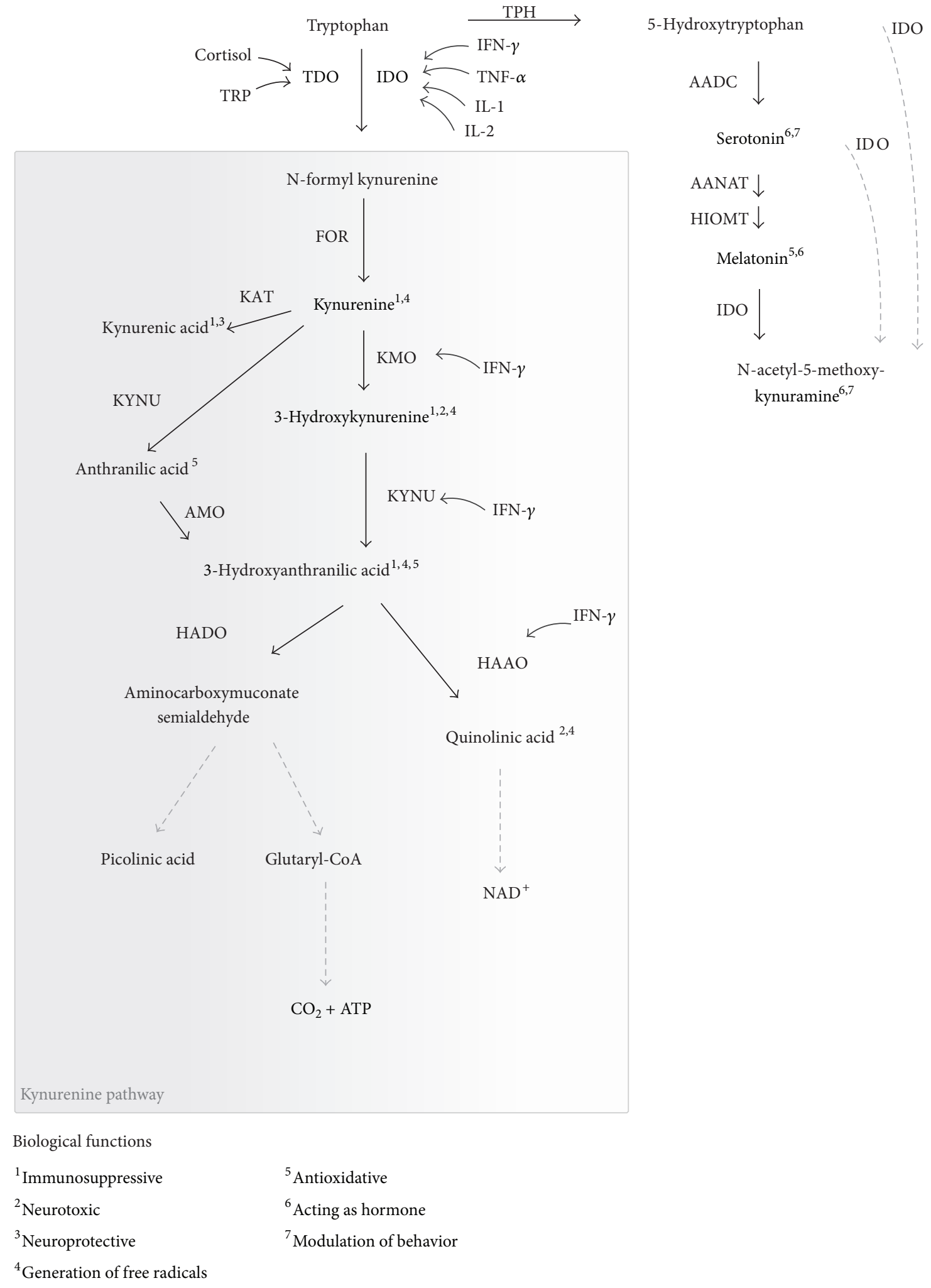
$\mathrm{N}$-acetyl-5-methoxy-
kynuramine

FIGURE 1: Main pathways of TRP degradation including enzymes and their potential stimuli (modified after $[1,4,16,35]$ ). Superscripted numbers indicate described biological effects of TRP metabolites. Black arrows mark enzymatic reactions and dashed arrows include more than one catalytic reaction step. Enzymes: FOR = formamidase, IDO = indolamine 2,3-dioxygenase; TDO = tryptophan 2,3-dioxygenase, TPH = tryptophan hydroxylase; $\mathrm{KAT}=$ kynurenine aminotransferase, $\mathrm{KMO}=$ kynurenine 3-monooxygenase; $\mathrm{KYNU}=$ kynureninase, $\mathrm{HADO}=$ 3-hydroxyanthranilic acid dioxygenase; $\mathrm{HAAO}=3$-hydroxyanthranilic acid oxidase, $\mathrm{AMO}=$ anthranilate 3-monooxygenase, and $\mathrm{AADC}=$ aromatic L-amino acid decarboxylase; AANAT = N-acetyltransferase; HIOMT = hydroxy-O-methyltransferase. 


\section{Regulation of LPS-Induced Expression of IDO1}

The ubiquitously expressed intracellular enzyme IDO is an oxidoreductase and catalyzes the degradation of L-TRP to $\mathrm{N}$-formylkynurenine, which, under physiologic conditions, is rapidly converted to KYN [36]. Thereby, L-TRP and KYN are transported bidirectionally by the L-amino acid transporter (LAT) to the IDO expressing cell or to the blood plasma, respectively [36]. The activation of IDO gene (Ido) expression is mainly induced by proinflammatory cytokines, but a constitutive expression of IDO has also been described $[27,37,38]$, indicating different physiological functions of IDO. LPS act as potential ligands for various cell types, such as peripheral mononuclear cells (PBMCs), endothelial cells, cells of smooth vascular muscles, granulocytes, or thrombocytes [39]. The activation of macrophages or monocytes by LPS initiates the release of bioactive lipids, reactive oxygen species, and cytokines including IFN- $\gamma$, TNF- $\alpha$, interleukin1 (IL-1), IL-6, IL-8, or IL-10, which induce synergistically, antagonistically, or independently acting signaling pathways [40]. The activation of immune cells by LPS is mainly mediated by toll-like receptor (TLR) 4 signaling, but also by TLR-2 [41]. Therefore, LPS interact with the soluble LPS binding protein (LPB). The LPS/LPB complex binds to the membrane protein cluster of differentiation 14 (CD14), which interacts with TLR-4 and activates nuclear factor "kappalight-chain-enhancer" of activated B-cells (NF- $\kappa$ B) associated signaling pathways $[42,43]$. The transcription factor NF$\kappa \mathrm{B}$ controls more than 150 target genes, which are essential for the expression of cytokines, immune receptors, antigenpresenting molecules, proteins of acute phase, and regulatory proteins, such as transcription factors or enzymes [44]. In addition to NF- $\kappa$ B associated IDO activation, IFN- $\gamma$ initiates the transcription of IDO through the pathway of a signal transducer and activator of transcription 1 (STAT1). In human cancer cells, it has been shown that IDO sustains its own expression via an autocrine AhR-IL-6-STAT3 signaling loop leading to a constitutive IDO expression in IDO positive tumor cells [45]. Ido genes have been identified in various species of mammals [46]. In mice and humans, Ido is located on chromosome eight and includes ten exons with approximately $15 \mathrm{kbp}$ of DNA [44]. The human Ido gene contains multiple promoter elements and the cDNA encodes a fulllength protein containing 403 amino acids with a molecular weight of $45 \mathrm{kDa}$ [27]. In addition, a truncated IDO1 variant, composed of 316 amino acids, has been described [30]. The expression and activity of the IDO enzyme is complex and is regulated on transcriptional, posttranscriptional, and posttranslational levels. On the transcriptional level, IFN- $\gamma$ induced IDO expression is controlled by the widely expressed adaptor protein bridging integrator 1 (BIN1) or the enteral fatty acid sodium butyrate $(\mathrm{NaB})$. A reduced expression or activity of BIN1, found in various types of cancers, enables an increased IDO activity, which promotes the appearance of immunotolerance [47-49]. In vitro studies of carcinoma cells demonstrated that $\mathrm{NaB}$ inhibits IFN- $\gamma$-induced IDO expression by reducing the phosphorylation and nuclear translocation of STAT1 [50]. The IDO enzyme is a monomeric protein containing a prosthetic heme group. The catalytic activity of IDO is posttranscriptionally regulated by the intracellular redox status, indicating the existence of an IDOspecific reducing system similar to that of erythrocytes $[25,51$, 52]. The oxidized enzyme (IDO-Fe ${ }^{3+}$ ) represents the catalytic inactive ferrous form, whereas the reduced ferric form of the enzyme (IDO- $\mathrm{Fe}^{2+}$ ) is catalytically active and enables the binding of TRP and oxygen [53]. Furthermore, there is evidence for $\mathrm{NaB}$-dependent ubiquitination of IDO as the preparation for proteasomal degradation [54]. In the context of inflammatory immune response, the release of IFN- $\gamma$ induces the generation of nitric-oxide (NO) by inducible nitric-oxide synthase (iNOS) [55]. NO is able to inhibit IDO activity in a reversible manner by building $\mathrm{IDO}^{2+} \mathrm{NO}-\mathrm{TRP}$ complex and preventing oxidation of TRP [56]. Furthermore, $\mathrm{NO}$ induces the degradation of IDO via mediating the binding of suppressor of cytokine signaling 3 (SOCS3) at a specific phosphotyrosine [57, 58]. An overview of the regulation mechanisms in response to inflammatory stimuli, such as LPS, is given by Figure 2 .

\section{The Kynurenine Pathway in Endotoxemia and Sepsis}

Dependent on dose and application, endotoxins, including LPS, induce the activation of inflammatory pathways, which can lead to serious systemic reactions, such as septic shock [59]. In animal models, the in vivo application of LPS is often used to simulate inflammatory conditions including systemic inflammatory response syndrome (SIRS), bacterial infection [60], or systemic inflammation [61]. Although the LPS-mediated activation of proinflammatory cytokines is essential for an adequate host defense, an overreaction of the proinflammatory immune response provokes serious tissue damage leading to life-threatening situations including septic shock [62]. In addition to the release of IL-10 [63], the activation of IDO is one potent immunosuppressive and regulatory mechanism of innate immunity. It has been shown that IDO expression in dendritic cells or macrophages suppresses $\mathrm{T}$ cells by depriving TRP [49, 64]. Additionally, it has been shown that KYN inhibits T cell-mediated inflammation by suppressing $\mathrm{T}$ cell proliferation [65]. Studies of human malignancies have found that IDO is highly expressed in many malignant tumor cells, leading to an effective immune escape by inhibiting the $\mathrm{T}$ cell response [47]. Furthermore, the generation of immunomodulating metabolites of the kynurenine pathway induced the arrest of $\mathrm{T}$ cells and the arrest or death of natural killer cells leading to the development of tolerogenic antigen-presenting cells (APCs) migrating to lymph nodes and mediating suppressive effects [14]. In humans, it has been shown that plasma concentrations of KYN are correlated with sepsis severity, demonstrating increased IDO activity in patients with septic shock [6]. The ratio of KYN to TRP is a sensitive marker for IDO activation and a significant increase can be used as a prognostic indicator for mortality in sepsis or trauma patients $[6,66]$. Interestingly, $\mathrm{KYN}$ is associated with the degree of hypotension in experimental human endotoxemia [67], 


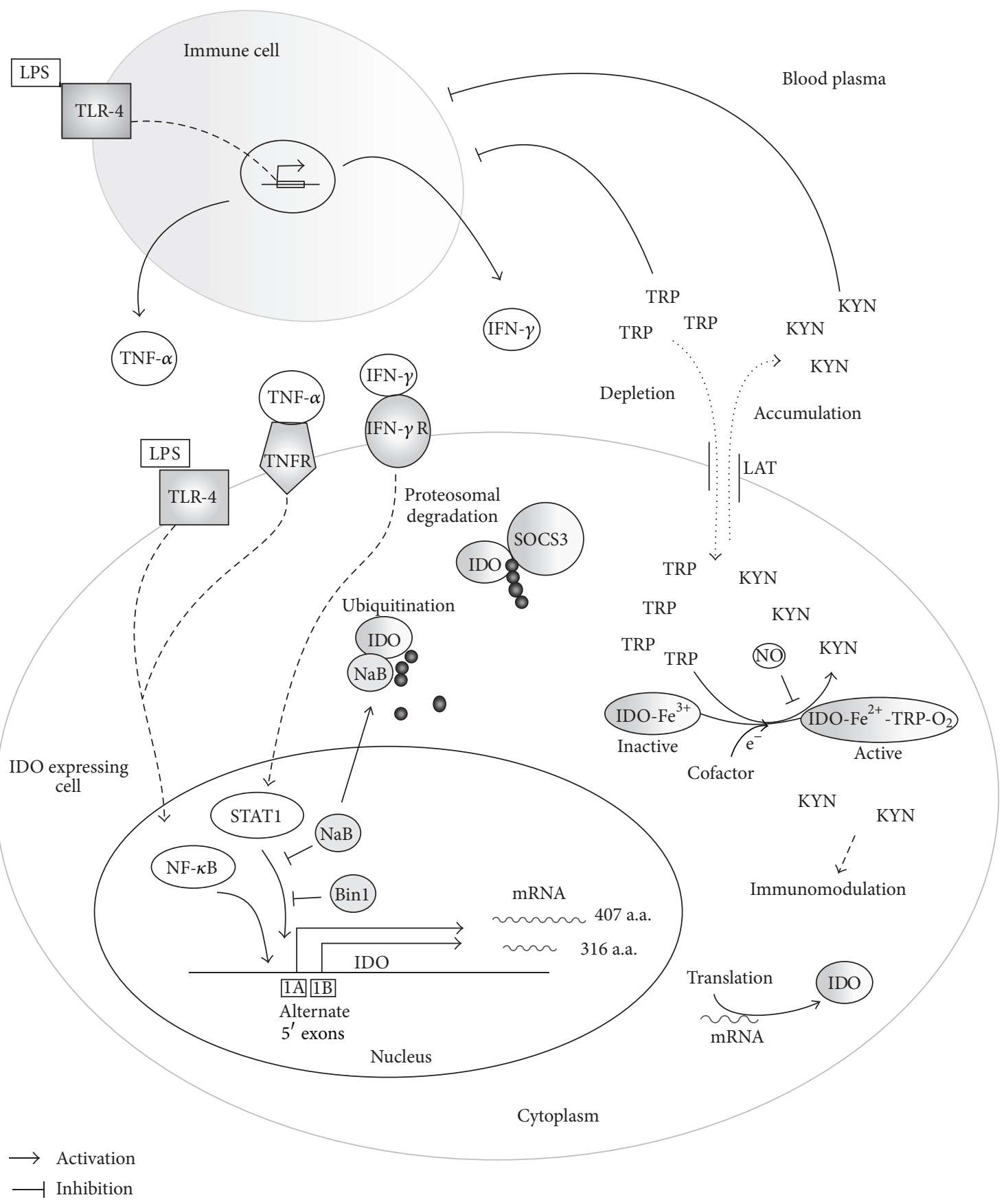

FIGURE 2: Schematic illustration of an inflammatory IDO activation by LPS and inflammatory cytokines and possible regulatory mechanisms on transcriptional, posttranscriptional, and posttranslational level.

indicating that there are functions of IDO activation other than in immunosuppression. This is supported by studies of IDO knockout mice and mice treated with the IDO inhibitor 1-methyltryptophan. After IDO knockout or inhibition, the mice showed decreased levels of proinflammatory TNF- $\alpha$, IL-6, and IL-12 but increased levels of the anti-inflammatory cytokine IL-10, which prevented them from dying from septic shock $48 \mathrm{~h}$ after the LPS challenge [68]. Furthermore, in this study, the balance of IL-12 to IL-10 had an impact on IDO protein expression, whereby IL-10 has suppressive effects on
IDO protein expression if IL-10 is much higher than IL-12. It is possible that the effects of IDO induced increased hypotension or a disturbance of the balance between pro- and antiinflammatory cytokine response. These are risk factors for mortality in early sepsis independent of immunosuppressive effects. Studies of patients with septic shock and acute kidney injury demonstrated that a failed reduction of KYNA after hemofiltration treatment may predict fatal outcomes [69]. It has been shown that KYNA in vitro inhibited the secretion of TNF- $\alpha$ by LPS treated mononuclear cells $[70,71]$. This 
was confirmed by studies of mice indicating that the in vivo application of KYNA provokes a reduced release of TNF- $\alpha$ in response to an ex vivo LPS challenge [71]. Furthermore, in an in vitro vascular flow model, KYNA triggered the firm arrest of monocytes to both fibronectin and intercellular adhesion molecule 1 (ICAM-1), via $\beta 1$ integrin- and $\beta 2$ integrinmediated mechanisms, respectively [72]. Notably, elevated plasma levels of KYNA have been reported in patients with inflammatory bowel diseases, but tryptophan and metabolites, such as 3-hydroxykynurenine, 3-hydroxyanthranilic acid, and xanthurenic acid were unchanged in all patients [73]. In vitro studies have also provided that KYNA acts as a ligand for the G protein-coupled receptor, GPR35, that is highly expressed in human peripheral monocytes and in cells of the gastrointestinal tract [70]. However, the involvement of GPR35 in gastrointestinal disorders and its immunosuppressive effects remain unclear.

\section{IDO-AhR-Mediated Immunosuppressive Effects on Endotoxin Tolerance and Cancer}

Endotoxin tolerance in vivo is characterized by a reduced inducibility of inflammatory cytokines and the HPA axis and a reduced development of illness symptoms including fever or weight loss in response to a repeated endotoxin challenge $[74,75]$. In the context of endotoxin-induced sepsis, the hyperinflammatory immune response is followed by a compensatory hypoinflammatory phase up to a complete paralysis of the immune system [76], which is characterized by an endotoxin tolerance. In this phase, the proper immune response failed, leading to secondary infections (e.g., ventilator-associated pneumonia) [77]. In addition to sepsis, endotoxin tolerance has been reported in several diseases including trauma, surgery, or pancreatitis. Recent studies on IDO knockout mice indicated that IDO1 plays a crucial role in the generation of LPS-induced endotoxin tolerance and the combined effects of AhR, IDO1, and transforming growth factor- $\beta$ (TGF- $\beta$ ) are required [78]. Notably, Lkynurenine alone failed to restore tolerance in the absence of IDO1, which indicates that nonenzymatic functions, such as intracellular signaling, are involved in the development of a regulatory phenotype in splenic dendritic cells. It has also been found that IDO1 specific phosphorylation reprograms gene expression leading to TGF- $\beta$ production in response to TLR signaling [79]. Interestingly, the phosphorylation of IDO1 in response to LPS is dependent on the upregulation of AhR [78], which triggers the activity of Src kinase [80] resulting in phosphorylation of the target proteins [81]. The importance of AhR activation and TGF- $\beta$ for the inducement of counterregulatory mechanisms, such as LPS tolerance, is supported by previous studies on mice indicating that the generation of regulatory $\mathrm{T}$ cells $\left(\mathrm{T}_{\text {regs }}\right)$ is dependent on AhR and TGF- $\beta[82,83]$. Notably, the suppressive activity of human T cells treated with TGF- $1 \beta$ plus TCDD as AhR ligand is greater than that of T cells treated only with TCDD [83]. The increase of $\mathrm{T}_{\text {regs }}$ is deleterious in sepsis patients and associated with decreased proliferation of effector $\mathrm{T}$ cells [84]. Participation of AhR in the transcriptional regulation of
LPS-induced gene expression is supported by further studies showing multiple AhR associated pathways [85-87]. It has been shown that AHR-deficient mice are more sensitive to endotoxin shock than wild type mice indicating the crucial role of AhR in modulating the TLR-4-induced inflammatory immune response [88]. It is possible that the lack of AhR in these animals prevents the successful establishment or maintenance of endotoxin tolerance as a counterregulatory mechanism in response to an endotoxin challenge. AhR is a ligand-dependent cytosolic transcription factor that is able to translocate to the cell nucleus after ligand binding [86]. The tryptophan metabolites L-kynurenine [78], 6formylindolcarbazole (FICZ, a photoproduct of TRP) [89], and KYNA [90] are described as natural AhR ligands mediating immunosuppressive functions. To induce transcription of AhR target genes in the nucleus, AhR partners with proteins such as AhR nuclear translocator (ARNT) or NF$\kappa \mathrm{B}$ subunit RelB. Studies on human cancer cells have shown that KYN activates the AhR-ARNT associated transcription of IL-6, which induced autocrine activation of IDO1 via STAT3. This AhR-IL-6-STAT3 loop is associated with a poor prognosis in lung cancer [45], supporting the idea that IDOmediated immunosuppression enables the immune escape of tumor cells. Notably, in trauma patients with increased IDO activity, nonsurvivors had higher concentrations of IL-6 after trauma than survivors [91]. It is possible that the autocrine constitutive activation of IDO is associated with immune dysfunctions and poor survival. The partnership of AhR and RelB has been shown to induce expression of IDO1 and IDO2 and to promote maturation of DCs promoting local tolerance at mucosal sites, such as the lungs or gut [86]. The prominence of AhR in immunosuppression and endotoxin tolerance may be a link between similar mechanisms found in inflammation and carcinogenesis. Potential connections between inflammatory IDO activation and AhR-mediated immunosuppressive pathways are shown in Figure 3.

However, to ensure a successful defense against pathogens, LPS tolerance is not a global downregulation of signaling proteins but is rather a mechanism of host defense that remains active [74]. In endotoxin-tolerant mice, increased numbers of Kupffer cells were detected leading to increased phagocytosis of bacteria [92, 93]. Furthermore, endotoxintolerant mice have an increased number of neutrophils, indicating the increased recruitment of cells from bone marrow [92] or reduced apoptosis [94]. In pigeons, a reduction of leukocytes and eosinophil granulocytes concurs with an increase in lymphocytes [95]. Even the composition of lymphocytes was changed in tolerant animals, whereas the percentage of cytotoxic T cells increased, but the percentage of T-helper cells remained unaltered. This would suggest that endotoxin tolerance helps to control inflammatory-mediated effects of bacterial infection. It was found that endotoxintolerant state protects mice against immunopathology in Gram-negative and Gram-positive infections [74]. Furthermore, in these studies endotoxin tolerance does not prevent the early events in protective TLR-2 signaling but prohibits the later onset of host's control over local or systemic disease. 


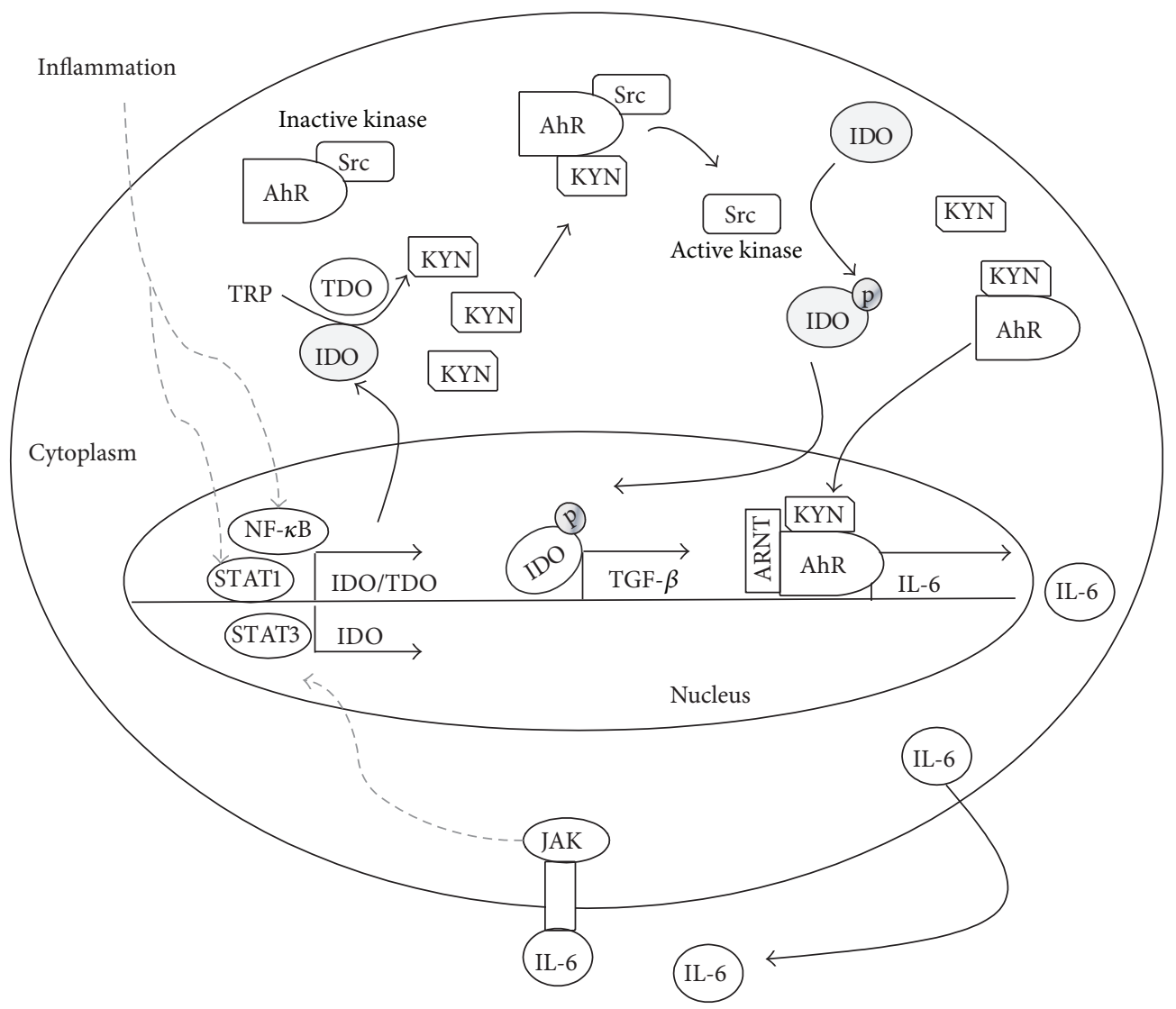

FIGURE 3: Schematic illustration of possible interaction between inflammatory IDO activation and AhR-mediated effects. IDO1 plays a crucial role in the generation of LPS-induced endotoxin tolerance whereas combined effects of AhR, IDO1, and TGF- $\beta$ are required. L-kynurenine alone failed to restore tolerance in the absence of IDO1 indicating nonenzymatic functions as intracellular signaling. It was found that IDO1 specific phosphorylation by AhR triggered kinase activity induces reprograming of gene expression leading to TGF- $\beta$ in response to TLR signaling. Studies on human cancer cells showed that IDO induced KYN activates the AhR-ARNT associated transcription of IL-6 which promotes autocrine activation of IDO1 via STAT3 supporting the theory that IDO-mediated immunosuppression enables effectively immune escape of tumor cells.

\section{From Immunosuppression to Immunoparalysis: The Significance of Enhanced IDO Activation}

The mechanisms that cause the development of immunoparalysis are poorly understood. However, it has been shown that the concept of endotoxin tolerance serves as an experimental analogue to the clinical entity of immunoparalysis [96]. Microarray studies of human PBMCs showed that the expression profile of sepsis patients is strongly associated with the signature for endotoxin tolerance. Furthermore, in early stage of sepsis, the risk for the development of a confirmed sepsis or organ dysfunction was predicted by this endotoxin tolerance signature [97]. The development of immunoparalysis is strongly associated with a poor outcome in patients because the homeostasis between pro- and antiinflammatory immune response is not restored within a few days [96]. Therefore, the protracted immunosuppressive phase prohibits the adequate control of the primary infection or of secondary hospital-acquired infections with opportunistic pathogens [98]. The role of IDO activation in the development of life-threatening immunoparalysis is still poorly understood. A recent report, which examined the AhR-mediated impact of IDO activation on immunosuppressive functions, such as LPS tolerance and immune escape of cancer cells, offers new insights for a better understanding of the development of cellular dysfunctions in immunoparalysis. It has been shown that enhanced IDO activity is associated with the severity of sepsis or septic shock $[6,66,91,99]$. The data indicate that patients with a poor outcome have enhanced IDO activity in the early stage of sepsis, leading to increased levels of KYN and KYNA, and provoking the expression of TGF- $\beta$ and IL- 6 and the development of endotoxin tolerance. Increased plasma levels of TGF$\beta$ and IL- 6 were found in early sepsis (day 1) of nonsurvivors compared to survivors [100]. Notably, in the ongoing sepsis of nonsurvivors (day 7), IL-6 did not significantly decrease in plasma, enabling the autocrine activation of IDO via the AhR-IL-6-STAT3 loop as described in human cells [45]. The theory of enhanced IDO activity and immunosuppression in ongoing sepsis is supported by data from patients with severe sepsis and septic shock. There, nonsurvivors had 


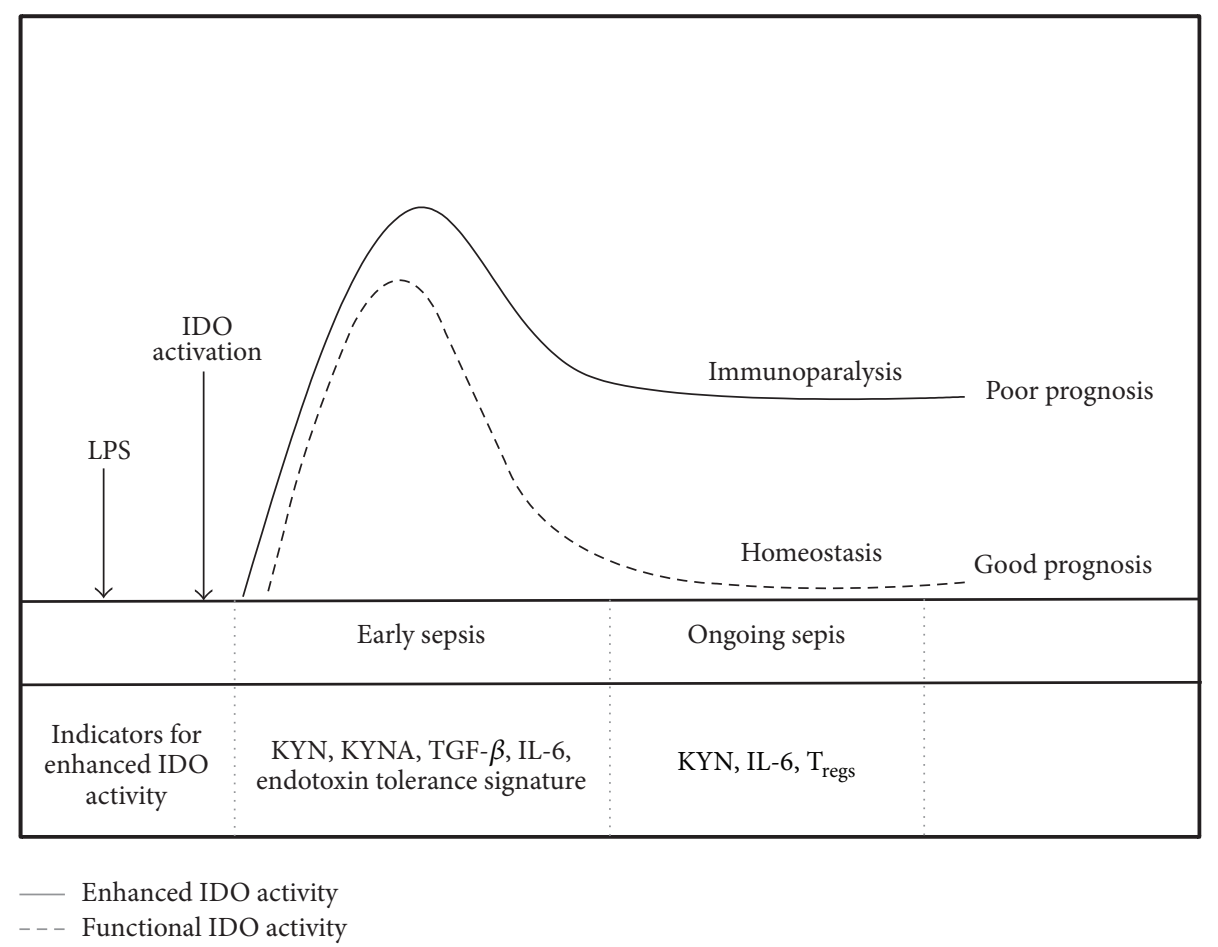

FIGURE 4: Enhanced IDO activity and its indicators as potential risk factors for the development of immunoparalysis and poor prognosis in sepsis. Patients with poor outcome have enhanced IDO activity in early state of sepsis leading to increased levels of KYN and KYNA that provokes expression of TGF- $\beta$, IL- 6 , and development of endotoxin tolerance. In ongoing sepsis, IL- 6 does not decrease significantly in plasma of nonsurvivors enabling the autocrine activation of IDO via AhR-IL-6-STAT3 loop. The enhanced IDO activity mediates immunosuppressive effects as increased generation of $\mathrm{T}_{\text {regs }}$ in ongoing sepsis, provoking the establishment of immunoparalysis.

elevated KYN/TRP ratios compared to survivors, even on day 7 of sepsis, indicating enhanced IDO activity [6]. Notably, in patients with sepsis-associated immunosuppression, the treatment with granulocyte-macrophage colony-stimulating factor (GM-CSF) reduced IDO activity and downstream metabolites significantly [101]. GM-CSF is known to restore the immunocompetence of monocytes in sepsis and may shorten the time of both intrahospital and intensive care unit stay [102]. These data support that enhanced IDO activity is one of several risk factors in poor prognosis of sepsis. An illustration of risk factors detected in early and ongoing sepsis that indicates significance of enhanced IDO activity for poor outcome is given in Figure 4.

At present, there are no data regarding the IDO gene or protein expression from early to ongoing sepsis. IDO activity is often measured indirectly by the KYN/TRP ratio but TRP is also depleted by TDO and IDO2. Studies on pigs have provided LPS-inducible IDO1 protein expression in the plasma $3 \mathrm{~h}$ and $6 \mathrm{~h}$ after the LPS challenge comparable with an increase of the metabolites KYN and KYNA [61]. Even in liver and lung tissue, IDO1 protein expression was detectable $6 \mathrm{~h}$ after LPS. One day after the LPS challenge, in both plasma and tissue, IDO1 protein expression was not detectable in LPS-challenged pigs in accordance with the normalization of pro- and anti-inflammatory cytokines and TRP metabolites. A second LPS challenge $24 \mathrm{~h}$ after the first challenge did not induce cytokine production indicating LPS tolerance.
However, IDO1 activation was induced neither in vivo nor ex vivo [103] suggesting that constitutive IDO1 activity is not required for maintenance of the tolerant state. It is possible that the initial phase of IDO activation is critical for a good or poor outcome after septic shock.

\section{Conclusion}

The IDO-mediated degradation of TRP along the kynurenine pathway plays a significant role as counterregulatory mechanism within the inflammatory immune response. Endotoxininduced IDO activation results in the depletion of TRP and the generation of biological active TRP metabolites such as KYN and KYNA which have important immunosuppressive properties. Furthermore, IDO-mediated effects are required for the establishment of LPS tolerance as anti-inflammatory mechanism permitting an adequate host defense. However, an imbalance in the cytokine activation and kynurenine cascade may result in severe immune dysfunctions as immunoparalysis. Studies of patients with sepsis found that an enhanced IDO activity was associated with an increased mortality risk. However, molecular mechanisms remained poorly understood. Recent findings of IDO-AhRmediated immunosuppressive effects in endotoxin tolerance and cancer offer new insights for the better understanding of molecular mechanisms in sepsis. In endotoxin tolerance, the AhR activation by KYN mediates the phosphorylation of 
IDO, inducing reprograming of gene expression and leading to TGF- $\beta$ production in response to TLR signaling. In cancer cells a constitutive IDO activation was associated with poor prognosis. This is provoked by immunosuppressive effects of IDO expressing tumor cells on the local environment, leading to an effective immune escape of the cancer cells. Notably, AhR also mediates the constitutive IDO expression in cancer cells. Thereby, KYN activates AhR-mediated transcription of IL-6 leading to an autocrine activation of a constitutive IDO expression. It has been shown that increased concentrations of $\mathrm{KYN}$ or KYNA, both ligands of $\mathrm{AhR}$, and increased concentrations of TGF- $\beta$ and IL- 6 are risk factors for establishment of an immunoparalysis and for a poor prognosis of patients in early sepsis instead of recovery. In ongoing sepsis, there are indices that prolonged IDO activity supports the maintenance of a protracted immunosuppressive phase. This might be due to the generation of regulatory $\mathrm{T}$ cells via TGF- $\beta$ mediated pathways and an increased production of immunosuppressive metabolites such as KYN or KYNA. Increased concentrations of IL-6, found in ongoing sepsis of patients with poor prognosis, may promote the constitutive IDO activation leading to maintenance of a life-threatening immunosuppressive phase in sepsis. The significance of IDO induced AhR-mediated effects on sepsis has still to be investigated. However, the molecular mechanisms of IDO induced immunosuppression, found in endotoxin tolerance and carcinogenesis, can offer new insights on critical pathways in sepsis-associated immunoparalysis and enable new approaches for therapeutic interventions.

\section{Abbreviations}

3-HA: 3-Hydroxyanthranilic acid

5-HT: $\quad$ Serotonin (5-hydroxytryptamine)

AA: $\quad$ Anthranilic acid

AhR: Aryl hydrocarbon receptor

APC: Antigen-presenting cell

ARNT: Aryl hydrocarbon receptor nuclear translocator

BIN1: Bridging integrator 1

CD: $\quad$ Cluster of differentiation

GM-CSF: Granulocyte-macrophage colony-stimulating factor

GPR35: G protein-coupled receptor

HPA: Hypothalamic-pituitary-adrenal

IDO: Indolamine 2,3-dioxygenase

IFN: Interferon

IL: Interleukin

iNOS: Inducible nitric-oxide synthase

KYN: Kynurenine

KYNA: Kynurenic acid

LBP: $\quad$ LPS binding protein

LPS: Lipopolysaccharides

$\mathrm{NaB}$ : $\quad$ Sodium butyrate

$\mathrm{NAD}^{+}$: Coenzyme nicotinamide adenine dinucleotide

NF- $\kappa$ B: Nuclear factor "kappa-light-chain-enhancer" of activated B-cells

NO: $\quad$ Nitric-oxide
PBMC: Peripheral mononuclear cell

QUIN: Quinolinic acid

RelB: Subunit of the NF- $\kappa$ B complex

SIRS: Systemic inflammatory response syndrome

SOCS3: Suppressor of cytokine signaling 3

STAT: Signal transducer and activator of transcription

TCDD: 2,3,7,8-Tetrachlorodibenzo-p-dioxin

TDO: Tryptophan 2,3-dioxygenase

TLR: Toll-like receptor

TNF: Tumor necrosis factor

TNFR: TNF receptor

TGF: Transforming growth factor

$\mathrm{T}_{\mathrm{reg}}$ : Regulatory $\mathrm{T}$ cell

TRP: Tryptophan

XA: Xanthurenic acid (3-hydroxykynurenic acid).

\section{Conflict of Interests}

Elisa Wirthgen and Andreas Hoeflich are related to Ligandis GbR. This relation has no effect on the content of the paper.

\section{Acknowledgments}

The authors thank Christian Manteuffel and the staff of Signal Transduction Unit from Leibniz Institute for Farm Animal Biology for helpful comments and suggestions. Furthermore, the authors thank Winfried Otten, Ellen Kanitz, Margret Tuchscherer, Ulrike Gimsa, and Christine Schütt for introducing in the topics tryptophan metabolism and neuroimmunoendocrinology.

\section{References}

[1] Y. Mándi and L. Vécsei, "The kynurenine system and immunoregulation," Journal of Neural Transmission, vol. 119, no. 2, pp. 197-209, 2012.

[2] O. Takikawa, "Biochemical and medical aspects of the indoleamine 2,3-dioxygenase-initiated L-tryptophan metabolism," Biochemical and Biophysical Research Communications, vol. 338, no. 1, pp. 12-19, 2005.

[3] D. H. Munn, M. Zhou, J. T. Attwood et al., "Prevention of allogeneic fetal rejection by tryptophan catabolism," Science, vol. 281, no. 5380, pp. 1191-1193, 1998.

[4] X. Liu, R. C. Newton, S. M. Friedman, and P. A. Scherle, "Indoleamine 2,3-dioxygenase, an emerging target for anticancer therapy," Current Cancer Drug Targets, vol. 9, no. 8, pp. 938-952, 2009.

[5] R. Huttunen, J. Syrjänen, J. Aittoniemi et al., "High activity of indoleamine 2, 3 dioxygenase enzyme predicts disease severity and case fatality in bacteremic patients," Shock, vol. 33, no. 2, pp. 149-154, 2010.

[6] P. Tattevin, D. Monnier, O. Tribut et al., "Enhanced indoleamine 2,3-dioxygenase activity in patients with severe sepsis and septic shock," Journal of Infectious Diseases, vol. 201, no. 6, pp. 956966, 2010.

[7] S. Erhardt, L. Schwieler, L. Nilsson, K. Linderholm, and G. Engberg, "The kynurenic acid hypothesis of schizophrenia," Physiology \& Behavior, vol. 92, no. 1-2, pp. 203-209, 2007. 
[8] G. J. Guillemin, K. R. Williams, D. G. Smith, G. A. Smythe, J. Croitoru-Lamoury, and B. J. Brew, "Quinolinic acid in the pathogenesis of Alzheimer's disease," in Developments in Tryptophan and Serotonin Metabolism, pp. 167-176, Springer, Berlin, Germany, 2003.

[9] J. C. O’Connor, M. A. Lawson, C. André et al., "Lipopolysaccharide-induced depressive-like behavior is mediated by indoleamine 2,3-dioxygenase activation in mice," Molecular Psychiatry, vol. 14, no. 5, pp. 511-522, 2009.

[10] R. Dantzer, J. C. O'Connor, M. A. Lawson, and K. W. Kelley, "Inflammation-associated depression: from serotonin to kynurenine," Psychoneuroendocrinology, vol. 36, no. 3, pp. 426436, 2011.

[11] J. R. Moffett and M. A. Namboodiri, "Tryptophan and the immune response," Immunology and Cell Biology, vol. 81, no. 4, pp. 247-265, 2003.

[12] J. Peters, "Tryptophan nutrition and metabolism: an overview," in Kynurenine and Serotonin Pathways, pp. 345-358, Springer, 1991.

[13] R. S. Grant, H. Naif, M. Espinosa, and V. Kapoor, "IDO induction in IFN- $\gamma$ activated astroglia: a role in improving cell viability during oxidative stress," Redox Report, vol. 5, no. 2-3, pp. 101-104, 2000.

[14] A. Gonzalez, N. Varo, E. Alegre, A. Diaz, and I. Melero, "Immunosuppression routed via the kynurenine pathway: a biochemical and pathophysiologic approach," Advances in Clinical Chemistry, vol. 45, pp. 155-197, 2008.

[15] J. P. Ruddick, A. K. Evans, D. J. Nutt, S. L. Lightman, G. A. W. Rook, and C. A. Lowry, "Tryptophan metabolism in the central nervous system: medical implications," Expert Reviews in Molecular Medicine, vol. 8, no. 20, pp. 1-27, 2006.

[16] T. W. Stone and L. G. Darlington, "Endogenous kynurenines as targets for drug discovery and development," Nature Reviews Drug Discovery, vol. 1, no. 8, pp. 609-620, 2002.

[17] Y. Wang, H. Liu, G. McKenzie et al., "Kynurenine is an endothelium-derived relaxing factor produced during inflammation," Nature Medicine, vol. 16, no. 3, pp. 279-285, 2010.

[18] F. Moroni, A. Cozzi, M. Sili, and G. Mannaioni, "Kynurenic acid: a metabolite with multiple actions and multiple targets in brain and periphery," Journal of Neural Transmission, vol. 119, no. 2, pp. 133-139, 2012.

[19] G. F. Oxenkrug, "Increased plasma levels of xanthurenic and kynurenic acids in type 2 diabetes," Molecular Neurobiology, vol. 52, no. 2, pp. 805-810, 2015.

[20] A. Pérez-González, J. R. Alvarez-Idaboy, and A. Galano, "Freeradical scavenging by tryptophan and its metabolites through electron transfer based processes," Journal of Molecular Modeling, vol. 21, article 213, 2015.

[21] V. Chobot, F. Hadacek, W. Weckwerth, and L. Kubicova, "Iron chelation and redox chemistry of anthranilic acid and 3-hydroxyanthranilic acid: a comparison of two structurally related kynurenine pathway metabolites to obtain improved insights into their potential role in neurological disease development," Journal of Organometallic Chemistry, vol. 782, pp. 103110, 2015.

[22] L. G. Darlington, C. M. Forrest, G. M. Mackay et al., "On the biological importance of the 3-hydroxyanthranilic acid: anthranilic acid ratio," International Journal of Tryptophan Research, vol. 3, no. 1, pp. 51-59, 2010.

[23] D. Krause, H.-S. Suh, L. Tarassishin et al., "The tryptophan metabolite 3-hydroxyanthranilic acid plays anti-inflammatory and neuroprotective roles during inflammation: role of hemeoxygenase-1," The American Journal of Pathology, vol. 179, no. 3, pp. 1360-1372, 2011.

[24] M. W. Taylor and G. Feng, "Relationship between interferon- $\gamma$, indoleamine 2, 3-dioxygenase, and tryptophan catabolism," The FASEB Journal, vol. 5, no. 11, pp. 2516-2522, 1991.

[25] S. R. Thomas and R. Stocker, "Redox reactions related to indoleamine 2,3-dioxygenase and tryptophan metabolism along the kynurenine pathway," Redox Report, vol. 4, no. 5, pp. 199-220, 1999.

[26] N. Le Floc'h, W. Otten, and E. Merlot, “Tryptophan metabolism, from nutrition to potential therapeutic applications," Amino Acids, vol. 41, no. 5, pp. 1195-1205, 2011.

[27] N. J. C. King and S. R. Thomas, "Molecules in focus: indoleamine 2,3-dioxygenase," The International Journal of Biochemistry and Cell Biology, vol. 39, no. 12, pp. 2167-2172, 2007.

[28] K. Ohira, H. Hagihara, K. Toyama et al., "Expression of tryptophan 2,3-dioxygenase in mature granule cells of the adult mouse dentate gyrus," Molecular Brain, vol. 3, no. 1, article 26, 2010.

[29] M. Kanai, T. Nakamura, and H. Funakoshi, "Identification and characterization of novel variants of the tryptophan 2, 3dioxygenase gene: differential regulation in the mouse nervous system during development," Neuroscience Research, vol. 64, no. 1, pp. 111-117, 2009.

[30] H. J. Ball, H. J. Yuasa, C. J. D. Austin, S. Weiser, and N. H. Hunt, "Indoleamine 2, 3-dioxygenase-2; a new enzyme in the kynurenine pathway," The International Journal of Biochemistry and Cell Biology, vol. 41, no. 3, pp. 467-471, 2009.

[31] H. J. Ball, A. Sanchez-Perez, S. Weiser et al., "Characterization of an indoleamine 2,3-dioxygenase-like protein found in humans and mice," Gene, vol. 396, no. 1, pp. 203-213, 2007.

[32] S. Löb, A. Königsrainer, D. Zieker et al., "IDO1 and IDO2 are expressed in human tumors: levo- but not dextro-1-methyl tryptophan inhibits tryptophan catabolism," Cancer Immunology, Immunotherapy, vol. 58, no. 1, pp. 153-157, 2009.

[33] L. M. F. Merlo, E. Pigott, J. B. DuHadaway et al., "IDO2 is a critical mediator of autoantibody production and inflammatory pathogenesis in a mouse model of autoimmune arthritis," The Journal of Immunology, vol. 192, no. 5, pp. 2082-2090, 2014.

[34] R. Metz, C. Smith, J. B. DuHadaway et al., "IDO2 is critical for IDO1-mediated T-cell regulation and exerts a non-redundant function in inflammation," International Immunology, vol. 26, no. 7, pp. 357-367, 2014.

[35] Z. Bohár, J. Toldi, F. Fülöp, and L. Vécsei, "Changing the face of kynurenines and neurotoxicity: therapeutic considerations," International Journal of Molecular Sciences, vol. 16, no. 5, pp. 9772-9793, 2015.

[36] S. Lancellotti, L. Novarese, and R. De Cristofaro, "Biochemical properties of indoleamine 2,3-dioxygenase: from structure to optimized design of inhibitors," Current Medicinal Chemistry, vol. 18, no. 15, pp. 2205-2214, 2011.

[37] R. Yoshida, T. Nukiwa, Y. Watanabe, M. Fujiwara, F. Hirata, and O. Hayaishi, "Regulation of indoleamine 2,3-dioxygenase activity in the small intestine and the epididymis of mice," Archives of Biochemistry and Biophysics, vol. 203, no. 1, pp. 343351, 1980.

[38] R. Yoshida, J. Imanishi, T. Oku, T. Kishida, and O. Hayaishi, "Induction of pulmonary indoleamine 2,3-dioxygenase by interferon," Proceedings of the National Academy of Sciences of the United States of America, vol. 78, no. 1, pp. 129-132, 1981. 
[39] E. T. Reitschel, T. Kirikae, F. U. Shade et al., "Bacterial endotoxin: molecular relationships of structure to activity and function," The FASEB Journal, vol. 8, no. 2, pp. 217-225, 1994.

[40] S. N. Vogel and M. M. Hogan, Role of Cytokines in EndotoxinMediated Host Responses, Oxford University Press, New York, NY, USA, 1990.

[41] R. P. Darveau, T.-T. T. Pham, K. Lemley et al., "Porphyromonas gingivalis lipopolysaccharide contains multiple lipid A species that functionally interact with both toll-like receptors 2 and 4," Infection and Immunity, vol. 72, no. 9, pp. 5041-5051, 2004.

[42] S. M. Dauphinee and A. Karsan, "Lipopolysaccharide signaling in endothelial cells," Laboratory Investigation, vol. 86, no. 1, pp. 9-22, 2006

[43] D. J. Kahler and A. L. Mellor, "T cell regulatory plasmacytoid dendritic cells expressing indoleamine 2,3 dioxygenase," in Dendritic Cells, vol. 188 of Handbook of Experimental Pharmacology, pp. 165-196, Springer, Berlin, Germany, 2009.

[44] H. L. Pahl, "Activators and target genes of Rel/NF- $\kappa$ B transcription factors," Oncogene, vol. 18, no. 49, pp. 6853-6866, 1999.

[45] U. M. Litzenburger, C. A. Opitz, F. Sahm et al., "Constitutive IDO expression in human cancer is sustained by an autocrine signaling loop involving IL-6, STAT3 and the AHR," Oncotarget, vol. 5, no. 4, pp. 1038-1051, 2014.

[46] H. J. Yuasa, M. Takubo, A. Takahashi, T. Hasegawa, H. Noma, and T. Suzuki, "Evolution of vertebrate indoleamine 2,3dioxygenases," Journal of Molecular Evolution, vol. 65, no. 6, pp. 705-714, 2007.

[47] C. Uyttenhove, L. Pilotte, I. Théate et al., "Evidence for a tumoral immune resistance mechanism based on tryptophan degradation by indoleamine 2,3-dioxygenase," Nature Medicine, vol. 9, no. 10, pp. 1269-1274, 2003.

[48] A. L. Mellor and D. H. Munn, "IDO expression by dendritic cells: tolerance and tryptophan catabolism," Nature Reviews Immunology, vol. 4, no. 10, pp. 762-774, 2004.

[49] D. H. Munn and A. L. Mellor, "IDO and tolerance to tumors," Trends in Molecular Medicine, vol. 10, no. 1, pp. 15-18, 2004.

[50] Y.-W. He, H.-S. Wang, J. Zeng et al., "Sodium butyrate inhibits interferon-gamma induced indoleamine 2,3-dioxygenase expression via STAT1 in nasopharyngeal carcinoma cells," Life Sciences, vol. 93, no. 15, pp. 509-515, 2013.

[51] Y. Iwamoto, I. S. M. Lee, R. Kido, and M. Tsubaki, “Tryptophan 2,3-dioxygenase in Saccharomyces cerevisiae," Canadian Journal of Microbiology, vol. 41, no. 1, pp. 19-26, 1995.

[52] N. D. Papadopoulou, M. Mewies, K. J. McLean et al., "Redox and spectroscopic properties of human indoleamine 2, 3dioxygenase and a His303Ala variant: implications for catalysis," Biochemistry, vol. 44, no. 43, pp. 14318-14328, 2005.

[53] T. Taniguchi, M. Sono, F. Hirata et al., "Indoleamine 2,3dioxygenase. Kinetic studies on the binding of superoxide anion and molecular oxygen to enzyme," The Journal of Biological Chemistry, vol. 254, no. 9, pp. 3288-3294, 1979.

[54] G.-M. Jiang, Y.-W. He, R. Fang et al., "Sodium butyrate downregulation of indoleamine 2,3-dioxygenase at the transcriptional and post-transcriptional levels," The International Journal of Biochemistry \& Cell Biology, vol. 42, no. 11, pp. 1840-1846, 2010.

[55] L. Lu, C. A. Bonham, F. G. Chambers et al., "Induction of nitric oxide synthase in mouse dendritic cells by IFN- $\gamma$, endotoxin, and interaction with allogeneic T cells: nitric oxide production is associated with dendritic cell apoptosis," The Journal of Immunology, vol. 157, no. 8, pp. 3577-3586, 1996.
[56] S. R. Thomas, A. C. Terentis, H. Cai et al., "Post-translational regulation of human indoleamine 2, 3-dioxygenase activity by nitric oxide," Journal of Biological Chemistry, vol. 282, no. 33, pp. 23778-23787, 2007.

[57] C. Orabona, M. T. Pallotta, C. Volpi et al., "SOCS3 drives proteasomal degradation of indoleamine 2,3-dioxygenase (IDO) and antagonizes IDO-dependent tolerogenesis," Proceedings of the National Academy of Sciences of the United States of America, vol. 105, no. 52, pp. 20828-20833, 2008.

[58] M. T. Pallotta, C. Orabona, C. Volpi, U. Grohmann, P. Puccetti, and F. Fallarino, "Proteasomal degradation of indoleamine 2, 3dioxygenase in $\mathrm{CD}^{+}$dendritic cells is mediated by suppressor of cytokine signaling 3 (SOCS3)," International Journal of Tryptophan Research, vol. 3, pp. 91-97, 2010.

[59] J. G. Wagner and R. A. Roth, "Neutrophil migration during endotoxemia," Journal of Leukocyte Biology, vol. 66, no. 1, pp. 10-24, 1999.

[60] R. C. Bone, R. A. Balk, F. B. Cerra et al., "Definitions for sepsis and organ failure and guidelines for the use of innovative therapies in sepsis. The ACCP/SCCM Consensus Conference Committee. American College of Chest Physicians/Society of Critical Care Medicine," Chest Journal, vol. 101, no. 6, pp. $1644-$ 1655, 1992.

[61] E. Wirthgen, M. Tuchscherer, W. Otten et al., "Activation of indoleamine 2, 3-dioxygenase by LPS in a porcine model," Innate Immunity, vol. 20, no. 1, pp. 30-39, 2014.

[62] C. Galanos and M. A. Freudenberg, "Mechanisms of endotoxin shock and endotoxin hypersensitivity," Immunobiology, vol. 187, no. 3, pp. 346-356, 1993.

[63] K. Asadullah, W. Sterry, and H. D. Volk, "Interleukin-10 therapy-review of a new approach," Pharmacological Reviews, vol. 55, no. 2, pp. 241-269, 2003.

[64] P. Hwu, M. X. Du, R. Lapointe, M. Do, M. W. Taylor, and H. A. Young, "Indoleamine 2,3-dioxygenase production by human dendritic cells results in the inhibition of T cell proliferation," Journal of Immunology, vol. 164, no. 7, pp. 3596-3599, 2000.

[65] P. Terness, T. M. Bauer, L. Röse et al., "Inhibition of allogeneic $\mathrm{T}$ cell proliferation by indoleamine 2,3-dioxygenaseexpressing dendritic cells: mediation of suppression by tryptophan metabolites," The Journal of Experimental Medicine, vol. 196, no. 4, pp. 447-457, 2002.

[66] D. Changsirivathanathamrong, Y. Wang, D. Rajbhandari et al., "Tryptophan metabolism to kynurenine is a potential novel contributor to hypotension in human sepsis," Critical Care Medicine, vol. 39, no. 12, pp. 2678-2683, 2011.

[67] J.-S. Padberg, M. Van Meurs, J. T. Kielstein et al., "Indoleamine2,3-dioxygenase activity in experimental human endotoxemia," Experimental \& Translational Stroke Medicine, vol. 4, no. 1, article 24, 2012.

[68] I. D. Jung, M.-G. Lee, J. H. Chang et al., "Blockade of indoleamine 2, 3-dioxygenase protects mice against lipopolysaccharide-induced endotoxin shock," The Journal of Immunology, vol. 182, no. 5, pp. 3146-3154, 2009.

[69] W. Dabrowski, T. Kocki, J. Pilat, J. Parada-Turska, and M. L. N. G. Malbrain, "Changes in plasma kynurenic acid concentration in septic shock patients undergoing continuous veno-venous haemofiltration," Inflammation, vol. 37, no. 1, pp. 223-234, 2014.

[70] J. Wang, N. Simonavicius, X. Wu et al., "Kynurenic acid as a ligand for orphan G protein-coupled receptor GPR35," Journal of Biological Chemistry, vol. 281, no. 31, pp. 22021-22028, 2006.

[71] C. Kiank, J.-P. Zeden, S. Drude et al., "Psychological stressinduced, IDO1-dependent tryptophan catabolism: implications 
on immunosuppression in mice and humans," PLoS ONE, vol. 5, no. 7, Article ID el1825, 2010.

[72] M. C. Barth, N. Ahluwalia, T. J. T. Anderson et al., "Kynurenic acid triggers firm arrest of leukocytes to vascular endothelium under flow conditions," The Journal of Biological Chemistry, vol. 284, no. 29, pp. 19189-19195, 2009.

[73] C. M. Forrest, S. R. Gould, L. G. Darlington, and T. W. Stone, "Levels of purine, kynurenine and lipid peroxidation products in patients with inflammatory bowel disease," Advances in Experimental Medicine and Biology, vol. 527, pp. 395-400, 2003.

[74] M. D. Lehner and T. Hartung, "Endotoxin tolerancemechanisms and beneficial effects in bacterial infection," in Reviews of Physiology, Biochemistry and Pharmacology, vol. 144 of Reviews of Physiology, Biochemistry and Pharmacology, pp. 95-141, Springer, Berlin, Germany, 2002.

[75] J. Li, D. F. Li, J. J. Xing, Z. B. Cheng, and C. H. Lai, "Effects of $\beta$-glucan extracted from Saccharomyces cerevisiae on growth performance, and immunological and somatotropic responses of pigs challenged with Escherichia coli lipopolysaccharide," Journal of Animal Science, vol. 84, no. 9, pp. 2374-2381, 2006.

[76] M. F. Osuchowski, K. Welch, J. Siddiqui, and D. G. Remick, "Circulating cytokine/inhibitor profiles reshape the understanding of the SIRS/CARS continuum in sepsis and predict mortality," Journal of Immunology, vol. 177, no. 3, pp. 1967-1974, 2006.

[77] J. S. Boomer, J. M. Green, and R. S. Hotchkiss, "The changing immune system in sepsis: is individualized immunomodulatory therapy the answer?" Virulence, vol. 5, no. 1, pp. 4556, 2014.

[78] A. Bessede, M. Gargaro, M. T. Pallotta et al., "Aryl hydrocarbon receptor control of a disease tolerance defence pathway," Nature, vol. 511, no. 7508, pp. 184-190, 2014.

[79] A. De Luca, C. Montagnoli, T. Zelante et al., "Functional yet balanced reactivity to Candida albicans requires TRIF, MyD88, and IDO-dependent inhibition of Rorc," Journal of Immunology, vol. 179, no. 9, pp. 5999-6008, 2007.

[80] B. Dong, W. Cheng, W. Li et al., "FRET analysis of protein tyrosine kinase c-Src activation mediated via aryl hydrocarbon receptor," Biochimica et Biophysica Acta (BBA): General Subjects, vol. 1810, no. 4, pp. 427-431, 2011.

[81] M. Backlund and M. Ingelman-Sundberg, "Regulation of aryl hydrocarbon receptor signal transduction by protein tyrosine kinases," Cellular Signalling, vol. 17, no. 1, pp. 39-48, 2005.

[82] J. D. Mezrich, J. H. Fechner, X. Zhang, B. P. Johnson, W. J. Burlingham, and C. A. Bradfield, "An interaction between kynurenine and the aryl hydrocarbon receptor can generate regulatory T cells," The Journal of Immunology, vol. 185, no. 6, pp. 3190-3198, 2010.

[83] R. Gandhi, D. Kumar, E. J. Burns et al., "Activation of the aryl hydrocarbon receptor induces human type 1 regulatory $\mathrm{T}$ celllike and Foxp $3^{+}$regulatory T cells," Nature Immunology, vol. 11, no. 9, pp. 846-853, 2010.

[84] F. Venet, C.-S. Chung, H. Kherouf et al., "Increased circulating regulatory T cells $\left(\mathrm{CD} 4^{+} \mathrm{CD} 25^{+} \mathrm{CD} 127^{-}\right)$contribute to lymphocyte anergy in septic shock patients," Intensive Care Medicine, vol. 35, no. 4, pp. 678-686, 2009.

[85] L. Stejskalova, Z. Dvorak, and P. Pavek, "Endogenous and exogenous ligands of aryl hydrocarbon receptor: current state of art," Current Drug Metabolism, vol. 12, no. 2, pp. 198-212, 2011.

[86] R. Thomas, "RelB and the aryl hydrocarbon receptor: dendritic cell tolerance at the epithelial interface," Immunology and Cell Biology, vol. 91, no. 9, pp. 543-544, 2013.
[87] F. J. Quintana, “The aryl hydrocarbon receptor: a molecular pathway for the environmental control of the immune response," Immunology, vol. 138, no. 3, pp. 183-189, 2013.

[88] H. Sekine, J. Mimura, M. Oshima et al., "Hypersensitivity of aryl hydrocarbon receptor-deficient mice to lipopolysaccharideinduced septic shock," Molecular and Cellular Biology, vol. 29, no. 24, pp. 6391-6400, 2009.

[89] R. P. Bunaciu and A. Yen, "6-Formylindolo (3,2-b)carbazole (FICZ) enhances retinoic acid (RA)-induced differentiation of HL-60 myeloblastic leukemia cells," Molecular Cancer, vol. 12, article 39, 2013.

[90] B. C. DiNatale, I. A. Murray, J. C. Schroeder et al., "Kynurenic acid is a potent endogenous aryl hydrocarbon receptor ligand that synergistically induces interleukin- 6 in the presence of inflammatory signaling," Toxicological Sciences, vol. 115, no. 1, pp. 89-97, 2010.

[91] M. Ploder, A. Spittler, K. Kurz et al., "Accelerated tryptophan degradation predicts poor survival in trauma and sepsis patients," International Journal of Tryptophan Research, vol. 3, pp. 61-67, 2010.

[92] M. D. Lehner, J. Ittner, D. S. Bundschuh, N. van Rooijen, A. Wendel, and T. Hartung, "Improved innate immunity of endotoxin-tolerant mice increases resistance to Salmonella enterica serovar typhimurium infection despite attenuated cytokine response," Infection and Immunity, vol. 69, no. 1, pp. 463-471, 2001.

[93] A. P. Bautista and J. J. Spitzer, "Acute endotoxin tolerance downregulates superoxide anion release by the perfused liver and isolated hepatic nonparenchymal cells," Hepatology, vol. 21, no. 3, pp. 855-862, 1995.

[94] C. Yamamoto, S.-I. Yoshida, H. Taniguchi, M. H. Qin, H. Miyamoto, and Y. Mizuguchi, "Lipopolysaccharide and granulocyte colony-stimulating factor delay neutrophil apoptosis and ingestion by guinea pig macrophages," Infection \& Immunity, vol. 61, no. 5, pp. 1972-1979, 1993.

[95] K. Dudek and D. Bednarek, "Cellular immune response of pigeons in the conditions of endotoxin fever and pyrogenic tolerance," Polish Journal of Veterinary Sciences, vol. 14, no. 1, pp. 127-133, 2011.

[96] W. J. Frazier and M. W. Hall, "Immunoparalysis and adverse outcomes from critical illness," Pediatric Clinics of North America, vol. 55, no. 3, pp. 647-668, 2008.

[97] O. M. Pena, D. G. Hancock, N. H. Lyle et al., "An endotoxin tolerance signature predicts sepsis and organ dysfunction at initial clinical presentation," EBioMedicine, vol. 1, no. 1, pp. 6471, 2014.

[98] R. S. Hotchkiss, G. Monneret, and D. Payen, "Sepsis-induced immunosuppression: from cellular dysfunctions to immunotherapy," Nature Reviews Immunology, vol. 13, no. 12, pp. 862-874, 2013.

[99] J.-P. Zeden, G. Fusch, B. Holtfreter et al., "Excessive tryptophan catabolism along the kynurenine pathway precedes ongoing sepsis in critically ill patients," Anaesthesia \& Intensive Care, vol. 38, no. 2, pp. 307-316, 2010.

[100] H.-P. Wu, C.-C. Shih, C.-Y. Lin, C.-C. Hua, and D.-Y. Chuang, "Serial increase of IL-12 response and human leukocyte antigenDR expression in severe sepsis survivors," Critical Care, vol. 15, no. 5, article R224, 2011.

[101] J. C. Schefold, J.-P. Zeden, R. Pschowski et al., “Treatment with granulocyte-macrophage colony-stimulating factor is associated with reduced indoleamine 2,3-dioxygenase activity and 
kynurenine pathway catabolites in patients with severe sepsis and septic shock," Scandinavian Journal of Infectious Diseases, vol. 42, no. 3, pp. 164-171, 2010.

[102] C. Meisel, J. C. Schefold, R. Pschowski et al., "Granulocytemacrophage colony-stimulating factor to reverse sepsisassociated immunosuppression: a double-blind, randomized, placebo-controlled multicenter trial," American Journal of Respiratory and Critical Care Medicine, vol. 180, no. 7, pp. 640-648, 2009.

[103] D.-B. E. Wirthgen, LPS-induzierte aktivierung des enzyms indolamin 2, 3-dioxygenase beim schwein: physiologische konsequenzen und ihre blockade durch 1-methyltryptophan [Ph.D. thesis], Universität Rostock, Rostock, Germany, 2012. 

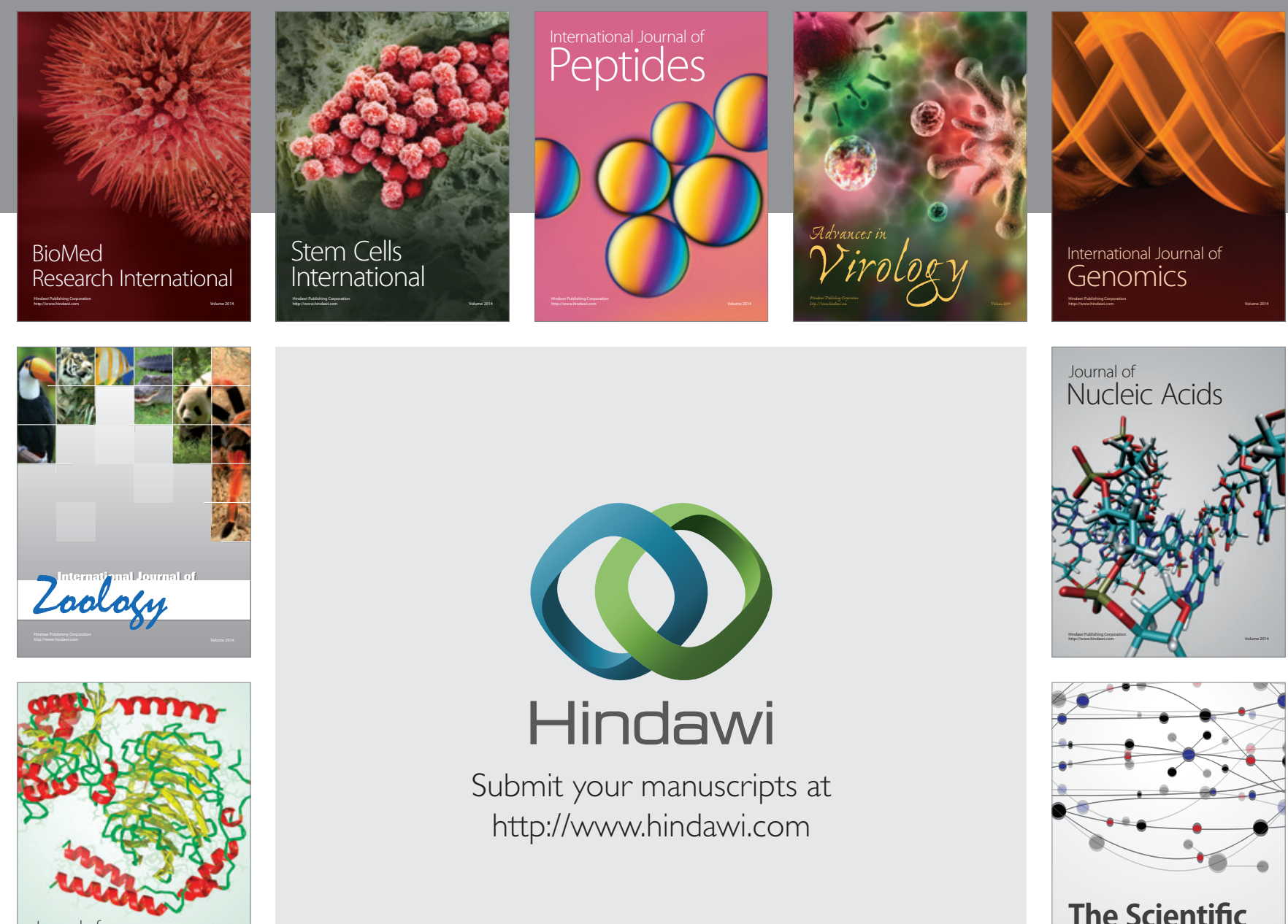

Submit your manuscripts at

http://www.hindawi.com

Journal of
Signal Transduction
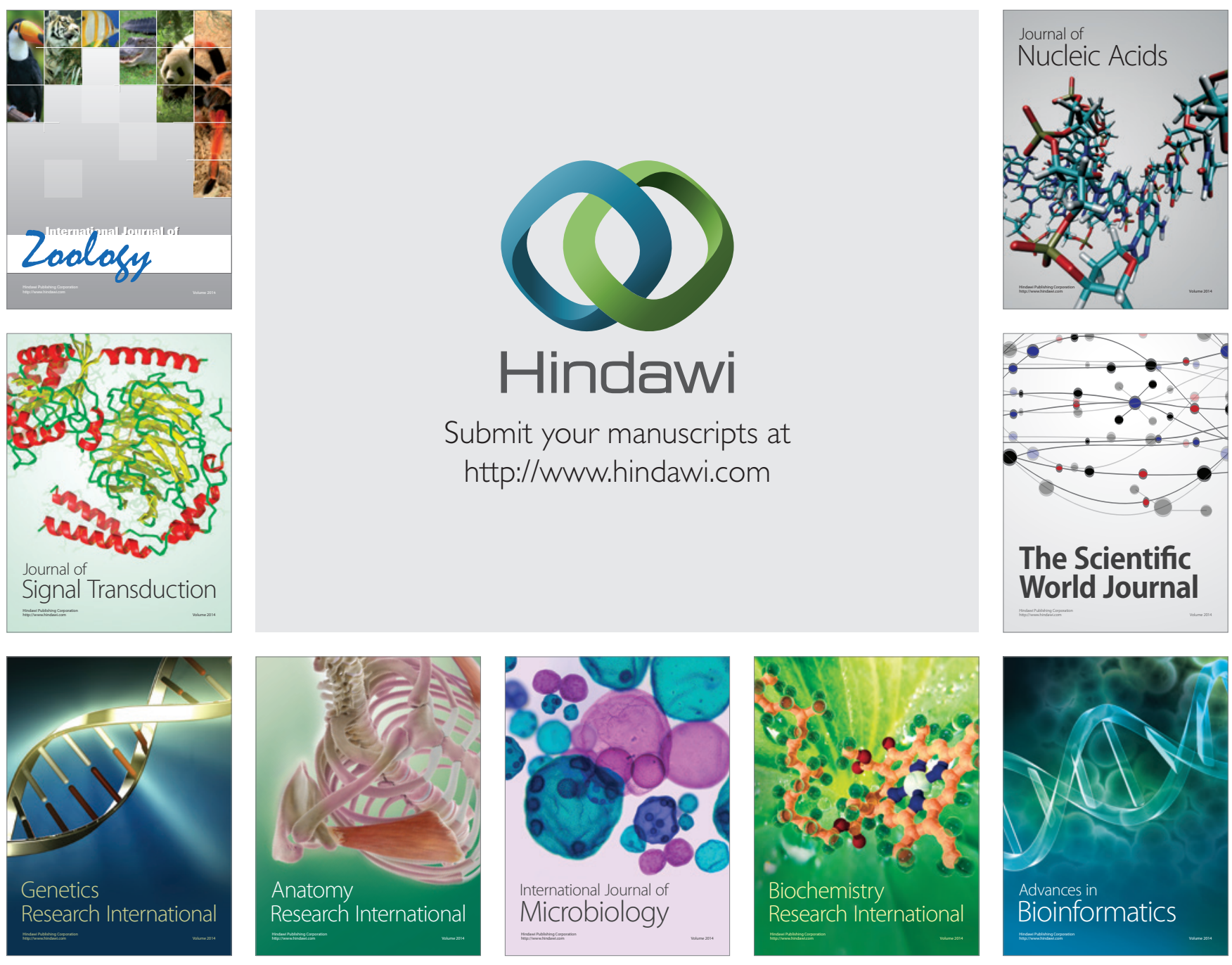

The Scientific World Journal
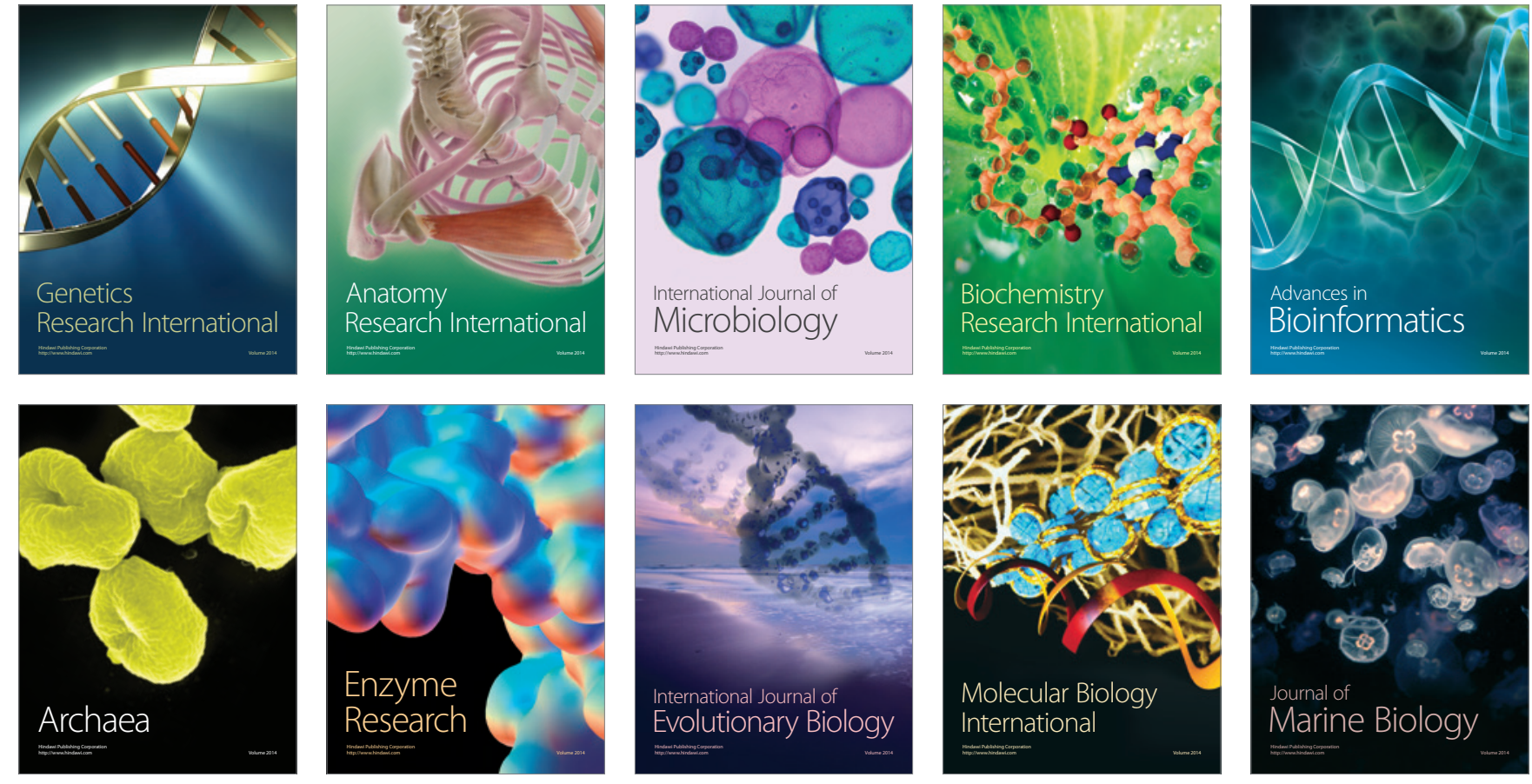